\title{
Insecticide Toxicity, Synergism and Resistance in Plutella xylostella (Lepidoptera: Plutellidae)
}

\author{
A. SOLEYMANZADE ${ }^{1 *}$, F. KHORRAMI ${ }^{1}$ and M. FOROUZAN ${ }^{2}$ \\ ${ }^{1}$ Department of Plant Protection, Faculty of Agriculture, Urmia University, Urmia, Iran \\ ${ }^{2}$ Plant Protection Research Department, West Azarbaijan Agricultural and Natural Resources Research Center, \\ AREEO, Urmia, Iran
}

(Received: 3 June 2018; accepted: 30 July 2018)

\begin{abstract}
Plutella xylostella has become particularly notorious for its resistance to various insecticides. The toxicities of abamectin, hexaflumuron and indoxacarb to third instar larvae of the pest were assayed using the leaf-dipping method. The results showed that abamectin and indoxacarb with the lowest LC50 values exhibited stronger toxicity to larvae than hexaflumuron. To determine the synergism of PBO, DEM, DEF and TPP on the toxicity of tested insecticides and demonstrating possible biochemical mechanisms, an abamectin-, a hexaflumuron- and an indoxacarb-resistant strain of P. xylostella were selected under laboratory conditions. After 10 generations of selection, the selected strains developed 14.21, 7.08, and 32.36-fold higher resistance to these insecticides, respectively. Abamectin resistance in abamectin-selected strain was suppressed with the synergists such as DEM and PBO, suggesting the involvement of monooxygeneses and glutathione S-transferase in the development of resistance in P. xylostella. Treatment with PBO and DEF significantly decreased the toxicity of hexaflumuron in the hexaflumuron-selected strain. Also, in indoxacarb-selected strain, the maximum synergism was occurred using PBO and DEF, followed by DEM and TPP. Hexaflumuron and indoxacarb synergism studies indicated in hexaflumuron resistance, monooxygenases and esterases, and in indoxacarb resistance, monooxygenases, esterases and glutathione S-transferae may be involved in the resistance mechanisms
\end{abstract}

Keywords: Resistance, synergist, Plutella xylostella, abamectin, hexaflumuron, indoxacarb.

Diamondback moth, Plutella xylostella L. (Lepidoptera: Plutellidae) is a major insect pest of cabbage plants worldwide (Gong et al., 2013). Most damage is caused by the larvae tunneling into the heads/foliage of host plants (Troczka et al., 2017). Insecticidal control is the main mean for suppression of diamondback moth damage (Sarfraz and Keddie, 2005; Sun et al., 2011; Furlong et al., 2013; Troczka et al., 2017). Many studies have revealed that P. xylostella has an ability to develop high level of resistance in a short time when a new pesticide is introduced (Talekar and Shelton, 1993; Zhao et al., 2006; Dukre et al., 2009; Liu et al., 2015; Troczka et al., 2017). The pest has shown different levels of resistances to many groups of insecticides and it is considered as one of the 20 critical resistant insect pests (Shelton et al., 2000). Insecticide resistance management (IRM) seeks to delay or prevent the evolution of resistance to pesticides. It also can aid in re-gaining susceptibility of a pest strain that has already developed some degree of resistance to a particular chemical insecticide. Among the main P. xylostella chemical control approaches, alteration or rotation of insecticides is one of the most simplest methods (Sparks and Nauen, 2015). 
Indoxacarb is a broad spectrum and effective insecticide against lepidopteran and some sucking insect pests. It belongs to oxidiazines class of insecticides and its mode of action is blocking the movement of sodium ions into certain nerve cell ion channels, paralyzing and finally killing the insect pest (Nehare et al., 2010). Abemectin is one of the most widely used insecticides for $P$. xylostella controlling in many parts of the world (Wang and $\mathrm{Wu}, 2014$ ). This compound is a natural fermentation product of the soil bacterium Streptomyces avermitilis (Memarizadeh et al., 2013) that acts on $y$-aminobutyric acid (GABA) and glutamate-gated chloride channels leading to the paralysis of pests (Stumpf and Nauen, 2002). Insect growth regulator (IGR) insecticides affect endocrine systems and cuticle formation (chitin synthesis inhibitor) and interrupt molting. Hexaflumuron, an IGR insecticide, is a chitin synthesis inhibitor that has been used to control a wide range of agricultural pests (Mahmoudvand et al., 2010, 2011).

Selected application of insecticides with different modes of actions is highly significant in an integrated pest management (IPM) strategy; it allows the prevention of resistance development in target organism, the determination of resistance patterns and consequently the risk assessment of resistance development (Brown and Payne, 1988; Liu et al., 2015; Fu et al., 2018).

Synergists elicit varying degrees of potential in each of four areas of IRM: Analytical tools, control of resistant strains, prevent of resistance and preserve of natural enemies. These compounds are the best research tools for overcoming metabolic resistance because they can directly inhibit the resistance mechanism (Raffa and Priester, 1985).

There are a few studies on abamectin and indoxacarb resistance in P. xylostella and there is no document about hexaflumuron resistance. There is a need to characterize resistance to these insecticides in P. xylostella due to their vast application in fields against different pests of cabbage crops.

In this research, an indoxacarb-resistant strain, an abamectin-resistant strain, and a hexaflumuron-resistant strain were established under laboratory conditions. For the resistant strains, synergism studies were performed to determine possible resistance mechanisms for indoxacarb, abamectin, and hexaflumuron. Such information will be important and is critically needed if we are going to design resistance management programs.

\section{Materials and Methods}

\section{Insect rearing and selection with abamectin, hexaflumuron, and indoxacarb}

The initial colony of P. xylostella was collected in August 2016 from an abandoned

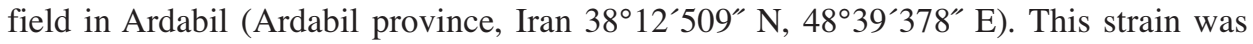
reared in the laboratory under insecticide-free conditions and its high susceptibility to evaluated insecticides was proven. Then, the strain was used as susceptible strain. Resistant strains (abamectin, hexaflumuron and indoxacarb resistant strains) were selected by applying these insecticides for 10 generations from susceptible strain. In each resistant strain, third-instar larvae of diamondback moth were exposed to cabbage (Brassica oleracea) leaves dipped in insecticides and mortality rates were counted after $48 \mathrm{~h}$. Then, surviving larvae were treated with fresh cabbage leaves. Based on former bioassays, $\mathrm{LC}_{50}$ value of each insecticide was applied to select each generation. For egg laying, 
about 400-500 adults of $P$. xylostella were placed in wooden cages $(50 \times 40 \times 30 \mathrm{~cm})$ containing potted radish seedlings (Raphanus sativus L.). Adults were fed on $10 \%$ honey-water solution. Potted radish seedlings were replaced every one or two days and then were transferred to greenhouse conditions (at $25 \pm 1{ }^{\circ} \mathrm{C}, 60-70 \%$ relative humidity $(\mathrm{RH})$ and photoperiod of $16: 8$ (L : D)) where the eggs were hatched. Finally, second instar larvae were transferred to larvae cages. After each generation of selection, toxicity of indoxacarb, abamectin, and hexaflumuron on third instar larvae of resistant strains were determined.

\section{Chemicals and insecticides}

Insecticides applied for bioassays were Indoxacarb (Avaunt ${ }^{\circledR}, 150 \mathrm{SC}$, DuPont, France), Hexaflumuron (Consult ${ }^{\circledR}, 10 \%$ EC, DowAgrosciences Company) and Abamectin (Vertimec ${ }^{\circledR}, 1.8$ EC, Partonar, Iran). Synergists, diethyl maleate (DEM), S,S,S-Tributylphosphorotrithioate (DEF), piperonylbutoxide (PBO) and triphenyl phosphate (TPP) were purchased from Sigma Aldrich Company (Taufkirchen, Germany).

\section{Bioassay}

Toxicities of abamectin, hexaflumuron, and indoxacarb on the third instar larvae of P. xylostella were evaluated using leaf-dipping method suggested by Shelton et al. (1993). Leaf discs of cabbage plant $(5.5 \mathrm{~cm}$ in diameter) were dipped in five concentrations of each insecticide for $20 \mathrm{~s}$ and allowed to dry at $25-27^{\circ} \mathrm{C}$ for $1-2 \mathrm{~h}$. Then, each leaf disc containing 20 third-instar larvae was transferred into a plastic Petri dish $(6 \mathrm{~cm}$ in diameter). For each concentration of each insecticide, three replicates with a total of 60 individuals were selected. Controls were treated with the same method with distilled water and Tween-80. Larvae were scored for mortality after $48 \mathrm{~h}$ and were counted as dead when having no response to fine-haired brush.

\section{Synergism test}

For the analysis of the effects of synergists on the toxicities of abamectin, hexaflumuron, and indoxacarb, the synergists PBO, DEM, DEF, and TPP were dissolved in acetone. Using leaf disc bioassay method as mentioned above, maximum sub-lethal doses of the synergists were determined to be $300,500,150$ and $90 \mathrm{mg}^{-1}$, respectively. The third instar larvae were treated topically with $0.5 \mu \mathrm{l}$ synergist solution on their dorsal thoracic segments ( $1 \mathrm{~h}$ before the experiments, they were fed with abamectin, hexaflumuron, and indoxacarb treated leaves). All above tests were performed in three replications and their mortality was assessed after $48 \mathrm{~h}$.

\section{Analysis}

Bioassay data were analyzed by probit analysis using SPSS v. 17.0. Synergism ratios (SRs) were counted by dividing the $\mathrm{LC}_{50}$ of insecticide alone by the $\mathrm{LC}_{50}$ of insecticide with synergist. Resistance ratios (RRs) were calculated by dividing $\mathrm{LC}_{50}$ of selected strain by $\mathrm{LC}_{50}$ of susceptible strain. 


\section{Results}

Toxicities of abamectin, hexaflumuron, and indoxacarb to P. xylostella

The results of leaf-dipping bioassays of abamectin, hexaflumuron, and indoxacarb on the third instar larvae of P. xylostella are shown in Table 1.

The obtained results demonstrate that abamectin and indoxacarb have good activities on the third instar larvae of $P$. xylostella. $\mathrm{LC}_{50}$ values for these compounds were obtained to be 2 and $2.82 \mathrm{mg} \mathrm{l}^{-1}$, respectively. Diamondback moth shows lower susceptibility to hexaflumuron $\left(\mathrm{LC}_{50}=17.31 \mathrm{mg} / \mathrm{l}\right)$.

Selection of abamectin, hexaflumuron, and indoxacarb resistances in susceptible strain

A susceptible strain of diamondback moth was continuously selected with abamectin, hexaflumuron, and indoxacarb for 10 generations in the laboratory conditions. The development trend of abamectin-, hexaflumuron- and indoxacarb-resistant strains are presented in Table 2. Selection of susceptible strain of P. xylostella with abamectin, hexaflu-

Table 1

Toxicity of abamectin, hexaflumuron and indoxacarb to third instar larvae of P. xylostella

\begin{tabular}{lcccc}
\hline Insecticide & $\mathrm{n}$ & Slope $\pm \mathrm{SE}$ & $\mathrm{LC}_{50}(\mathrm{mg} / \mathrm{l})$ & $\mathrm{x}^{2}(\mathrm{df})$ \\
\hline Abamectin & 300 & $1.52 \pm 0.20$ & $2.00(1.53-2.82)$ & $0.95(3)$ \\
Hexaflumuron & 300 & $1.09 \pm 0.23$ & $17.41(13.56-23.09)$ & $0.98(3)$ \\
Indoxacarb & 300 & $1.37 \pm 0.18$ & $2.82(2.05-4.04)$ & $1.57(3)$ \\
\hline
\end{tabular}

Table 2

Selection of resistance to abamectin, hexaflumuron and indoxacarb in different generations of P. xylostella

\begin{tabular}{lcccccc}
\hline Insecticide & Generation & $\mathrm{n}$ & Slope $\pm \mathrm{SE}$ & $\mathrm{LC}_{50}(\mathrm{mg} / \mathrm{l})$ & $\mathrm{x}^{2}(\mathrm{df})$ & $\mathrm{RR}^{\mathrm{a}}$ \\
\hline Abamectin & $\mathrm{G} 0$ & 300 & $1.21 \pm 0.20$ & $2.00(1.53-2.82)$ & $0.95(3)$ & 1.00 \\
& $\mathrm{G} 2$ & 300 & $1.70 \pm 0.28$ & $4.12(3.37-5.18)$ & $0.83(3)$ & 2.06 \\
& $\mathrm{G} 5$ & 300 & $2.41 \pm 0.45$ & $15.50(13.62-17.92)$ & $1.23(3)$ & 7.75 \\
& $\mathrm{G} 8$ & 300 & $2.67 \pm 0.40$ & $20.05(17.39-23.56)$ & $0.70(3)$ & 10.02 \\
& $\mathrm{G} 10$ & 300 & $1.57 \pm 0.26$ & $28.43(22.84-36.43)$ & $0.35(3)$ & 14.21 \\
\hline Hexaflumuron & $\mathrm{G} 0$ & 300 & $1.37 \pm 0.23$ & $17.41(13.56-23.09)$ & $0.98(3)$ & 1.00 \\
& $\mathrm{G} 2$ & 300 & $1.54 \pm 0.26$ & $21.68(17.35-27.87)$ & $1.09(3)$ & 1.25 \\
& $\mathrm{G} 5$ & 300 & $3.00 \pm 0.49$ & $66.95(59.71-76.23)$ & $0.13(3)$ & 3.84 \\
& $\mathrm{G} 8$ & 300 & $3.32 \pm 0.56$ & $104.46(94.18-117.40)$ & $2.02(3)$ & 6.00 \\
& $\mathrm{G} 10$ & 300 & $4.03 \pm 0.67$ & $123.42(113.23-135.54)$ & $1.09(3)$ & 7.08 \\
\hline Indoxacarb & $\mathrm{G} 0$ & 300 & $1.09 \pm 0.18$ & $2.82(2.05-4.04)$ & $1.57(3)$ & 1.00 \\
& $\mathrm{G} 2$ & 300 & $1.32 \pm 0.22$ & $5.59(4.30-7.51)$ & $1.02(3)$ & 1.98 \\
& $\mathrm{G} 5$ & 300 & $1.89 \pm 0.32$ & $15.26(12.72-18.74)$ & $1.22(3)$ & 5.41 \\
& $\mathrm{G} 8$ & 300 & $2.92 \pm 0.48$ & $54.99(48.89-62.80)$ & $1.30(3)$ & 19.5 \\
& $\mathrm{G} 10$ & 300 & $4.90 \pm 0.81$ & $91.25(85.08-98.77)$ & $0.70(3)$ & 32.36 \\
\hline
\end{tabular}

${ }^{\mathrm{a}} \mathrm{RR}$ resistance ratio at $\mathrm{LC}_{50}$ level $=\mathrm{LC}_{50}$ of the resistant strain to $\mathrm{LC}_{50}$ of susceptible (Ardabil) strain. 
Table 3

Toxicity of abamectin, hexaflumuron and indoxacarb with and without synergists on third instar larva of P. xylostella

\begin{tabular}{lcccccc}
\hline Insecticide & Synergist & $\mathrm{n}$ & Slope $\pm \mathrm{SE}$ & $\mathrm{LC}_{50}(\mathrm{mg} / \mathrm{l})$ & $\mathrm{x}^{2}(\mathrm{df})$ & $\mathrm{SR}^{\mathrm{a}}$ \\
\hline Abamectin & None & 300 & $1.57 \pm 0.26$ & $28.43(22.84-36.43)$ & $0.35(3)$ & - \\
& $\mathrm{DEF}$ & 300 & $1.32 \pm 0.22$ & $18.56(14.30-24.93)$ & $0.98(3)$ & 1.53 \\
& $\mathrm{DEM}$ & 300 & $1.88 \pm 0.32$ & $12.70(10.60-15.61)$ & $1.20(3)$ & 2.24 \\
& $\mathrm{PBO}$ & 300 & $2.08 \pm 0.28$ & $6.61(5.65-7.89)$ & $0.98(3)$ & 4.30 \\
& $\mathrm{TPP}$ & 300 & $2.19 \pm 0.36$ & $21.97(18.78-26.24)$ & $0.93(3)$ & 1.29 \\
\hline Hexaflumuron & None & 300 & $4.03 \pm 0.67$ & $123.42(113.23-135.54)$ & $1.09(3)$ & - \\
& DEF & 300 & $1.70 \pm 0.28$ & $56.24(45.93-70.69)$ & $1.14(3)$ & 2.19 \\
& DEM & 300 & $3.07 \pm 0.51$ & $77.92(69.66-88.43)$ & $0.81(3)$ & 1.58 \\
& PBO & 300 & $2.19 \pm 0.36$ & $33.16(28.34-39.60)$ & $1.03(3)$ & 3.72 \\
& TPP & 300 & $2.75 \pm 0.50$ & $93.76(82.75-107.95)$ & $1.04(3)$ & 1.32 \\
\hline Indoxacarb & None & 300 & $4.90 \pm 0.81$ & $91.25(85.08-98.77)$ & $0.70(3)$ & - \\
& DEF & 300 & $3.08 \pm 0.51$ & $25.88(23.14-29.36)$ & $0.72(3)$ & 3.53 \\
& DEM & 300 & $2.41 \pm 0.40$ & $40.03(34.72-47.17)$ & $0.67(3)$ & 2.28 \\
& PBO & 300 & $2.14 \pm 0.36$ & $13.89(11.83-16.67)$ & $1.99(3)$ & 6.57 \\
& TPP & 300 & $2.02 \pm 0.34$ & $47.22(39.85-57.20)$ & $0.99(3)$ & 1.93 \\
\hline
\end{tabular}

${ }^{\mathrm{a}} \mathrm{SR}$, synergistic ratio $=\mathrm{LC}_{50}$ of insecticide alone $/ \mathrm{LC}_{50}$ of insecticide + synergist.

muron, and indoxacarb produced resistant strains with 14.21-, 7.08- and 32.36-fold resistance, respectively, after 10 generations. In hexaflumuron selection process resistance development was slowed down, but this process in indoxacarb selection was fast. Compared with indoxacarb and hexaflumuron, resistance development for abamectin was moderate.

Synergism of PBO, DEF, DEM and TPP to abamectin, hexaflumuron, and indoxacarb

The synergisms of PBO, DEM, DEF and TPP on abamectin, hexaflumuron, and indoxacarb were tested in susceptible and resistant strains of $P$. xylostella. The obtained results are presented in Table 3. PBO showed an obvious synergism effect in three resistant strains. PBO synergistic ratios were 4.30, 3.72 and 6.57 for abamectin-, hexaflumuron-, and indoxacarb-resistant strains, respectively. In hexaflumuron resistant strain, no significant changes in mortality were found when TPP and DEM treatments were applied in conjunction with hexaflumuron and no synergistic effect was observed either for resistant strain or for susceptible strain. But in abamectin and indoxacarb resistant strains, DEM displays a moderate synergism (SRs were 2.24 and 2.28, respectively). DEF enhances the toxicities of abamectin, hexaflumuron, and indoxacarb to resistant strains by 1.53-, 2.19and 3.53-fold, respectively.

\section{Discussion}

Results of this study indicated that abamectin and indoxacarb had significant effects on larval stage of $P$. xylostella because they exhibited lower $\mathrm{LC}_{50}$ values $(2.00$ and 
$2.82 \mathrm{mg} \mathrm{l}^{-1}$, respectively). Larvicidal effect of hexaflumuron was also moderate $\left(\mathrm{LC}_{50}=17.41 \mathrm{mg} \mathrm{l}^{-1}\right)$. Mahmoudvand et al. (2010) evaluated the effects of indoxacarb and hexaflumuron on eggs and larvae of $P$. xylostella and reported that these insecticides were highly toxic to larvae of P. xylostella. Anjum and Wright (2016) evaluated the toxicity of different insecticides to P. xylostella and their results indicated that abamectin with lower LC $_{50}$ value, was more toxic to the pest. Fauziah (1990) evaluated the toxicity of three IGR insecticides (chlorfluazuron, teflubenzuron, and diflubenzuron) and abamectin against $P$. xylostella. Results indicated that abamectin was more toxic to pest than other insecticides. Our findings are in agreement with the results of the above authors.

To investigate the resistance development, susceptible strain was selected with abamectin, hexaflumuron, and indoxacarb for 10 generations. After 10 generations of selection, resistance ratios for abamectin ( $R R=14.21)$, hexaflumuron ( $R R=7.08)$, and indoxacarb $(R R=32.36)$ resistant strains were increased compared with susceptible (Ardabil) population (Table 2). These results are consistent with findings reported by some other researchers. Similarly, Nehare et al. (2010) reported a 31.30-fold increase in indoxacarb resistance in P. xylostella after selecting the field-collected population for 10 generations. Iqbal and Wright (1997) also selected insecticide-susceptible strain of P. xylostella with abamectin and teflubenzuron insecticides. They reported 3.7- and 15-fold resistance ratios for these insecticides, respectively. The rapid increase in P. xylostella resistance over selection of teflubenzuron pressure for only several generations has also been reported by Furlong and Wright (1994). To assess an effective IRM program, there is a necessity to prevent resistance development in crop systems and these are significant information in IRM strategies of P. xylostella.

Synergists, as research tools, can help to define the potential toxicity of an insecticide, and they also can aid in determining the particular mechanisms of insecticide resistance encountered. However, these compounds are effective only when resistance is due to enzyme-based resistance mechanisms (Raffa and Priester, 1985; Koou et al., 2014). To investigate possible mechanisms of resistance, we used synergists PBO (mixed function oxidase inhibitor), DEF (esterases inhibitor), DEM (gluthation S-transferase inhibitor) and TPP (carboxyesterase inhibitor). Resistance to amabectin in abamectin-selected strain was affected by DEM and PBO suggesting that monooxygenases and glutathione S-transferase detoxification enzymes may be involved in the main mechanisms of resistance in this strain. Hexaflumuron resistance in hexaflumuron-selected strain was reduced to 3.72- and 2.19-fold with PBO and DEF, respectively. This result suggested that monooxygenases and esterases may be the main metabolic enzymes involved in the resistance of diamondback moth to hexaflumuron. In indoxacarb-selected strain, maximum synergism was occurred using PBO, followed by DEF. The synergism ratios obtained by DEM and TPP were 2.28 and 1.93 compared to the susceptible strain. Thus, these synergists also had moderate synergism effects on indoxacarb. Nehare et al. (2010) reported that PBO, DEM, and TPP showed synergism with indoxacarb and played a key role in suppressing indoxacarb resistance in P. xylostella. Fauziah (1990) found that chlorfluazuronand teflubenzuron-selected strains of diamondback moth pre-treated with PBO and DEF showed increased susceptibility to these insecticides and suggested that monooxygenase and esterase may be involved in resistance. Campos et al. (1996) found that in abamectin resistant strain of Tetranychus urticae Koch, abamectin could be synergized 7.9-folds by DEF and they reported that PBO had relatively low synergistic ratio. 
Based on our results and since there is limited knowledge about resistance of P. xylostella to chemical insecticides, it is recommended to carry out comprehensive studies on various mechanisms of resistance, especially hexaflumuron resistance. Insecticides with cross-resistance share some resistance mechanisms and treatment with one of insecticides may result in resistance to all of them. Hence, these insecticides cannot be used rotationally. For the management of resistance to abamectin, hexaflumuron, and indoxacarb, studying on cross resistance patterns between these insecticides with other novel insecticides is recommended.

\section{Literature}

Anjum, F. and Wright, D. (2016): Relative toxicity of insecticides to the crucifer pests Plutella xylostella and Myzus persicae and their natural enemies. Crop Prot. 88, 131-136.

Brown, T. M. and Payne, G. T. (1988): Experimental selection for insecticide resistance. J. Econ. Entomol. 81, 49-56.

Campos, F., Krupa, D. A. and Dybas, R. A. (1996): Susceptibility of populations of two-spotted spider mites (Acari: Tetranychidae) from Florida, Holland, and the Canary Islands to abamectin and of abamectin resistance. J. Econ. Entomol. 89, 594-601.

Dukre, A. S., Moharil, M. P., Ghodki, B. S. and Rao, N. G. (2009): Role of glutathione S-transferase in imparting resistance to pyrethroids in Plutella xylostella (L.). Int. J. Integr. Bio. 6, 17-21.

Fauziah, I. (1990): Studies on resistance to acylurea compounds in Plutella xylostella L. (Lepidoptera: Yponomeutidae). $\mathrm{PhD}$ thesis. University of London, $259 \mathrm{p}$.

Fu, B., Li, Q., Qiu, H., Tang, L., Zeng, D., Liu, K. and Gao, Y. (2018): Resistance development, stability, cross resistance potential, biological fitness and biochemical mechanisms of spinetoram resistance in Thrips hawaiiensis (Thysanoptera: Thripidae). Pest Manage. Sci. 74, 1564-1574.

Furlong, M. J. and Wright, D. J. (1994): Examination of stability of restistance and cross-resistance patterns to acylurea insect growth regulators in field populations of the diamondback moth, Plutella xylostella, from Malaysia. Pestic. Sci. 42, 315-326.

Furlong, M. J., Wright, D. J. and Dosdall, L. M. (2013): Diamondback moth ecology and management: problems, progress, and prospects. Annu. Rev. Entomol. 58, 517-541.

Gong, Y. J., Wang, Z. H., Shi, B. C., Kang, Z. J., Zhu, L., Jin, G. H. and Weig, S. J. (2013): Correlation between pesticide resistance and enzyme activity in the diamondback moth, Plutella xylostella. J. Insect. Sci. $13,1-13$.

Iqbal, M. and Wright, D. J. (1997): Evaluation of resistance, cross resistance, and synergism of abamectin and teflubenzuron in a multi-resistant field population of Plutella xylostella (Lepidoptera: Plutellidae). Bull. Entomol. Res. 87, 481-486.

Koou, S. Y., Chong, C. S., Vythilingam, I., Ng, L. C. and Lee, C. Y. (2014): Pyrethroid resistance in Aedesa egypti larvae (Diptera: Culicidae) from Singapore. J. Med. Entomol. 51, 170-181.

Liu, X., Wang, H. Y., Ning, Y. B., Qiao, K. and Wang, K. Y. (2015): Resistance selection and characterization of chlorantraniliprole resistance in Plutella xylostella (Lepidoptera: Plutellidae). J. Econ. Entomol.108, 1978-1985.

Mahmoudvand, M., Abbasipour, H., Sheikhi Garjan, A. and Bandani, A. R. (2010): Effectiveness of indoxacarb and hexaflumuron on eggs, larvae and adults of Plutella xylostella (L.) (Lepidoptera: Yponomeutidae). Acta Entomol. Sin. 53, 1424-1428.

Mahmoudvand, M., Abbasipour, H., Sheikhi Garjan, A. and Bandani, A. R. (2011): Sublethal effects of hexaflumuron on development and reproduction of the diamondback moth, Plutella xylostella (Lepidoptera: Yponomeutidae). Insect Sci. 18, 689-696.

Memarizadeh, N., Ghadamyari, M., Zamani, P. and Sajedi, R. H. (2013): Resistance mechanisms to abamectin in Iranian populations of the two-spotted spider mite, Tetranychus urticae Koch (Acari: Tetranichidae). Acarologia 53, 235-246. 
Nehare, S., Moharil, M. P., Ghodki, B. S., Lande, G. K., Bisane, K. D., Thakare, A. S. and Barkhade, U. P. (2010): Biochemical analysis and synergistic suppression of indoxacarb resistance in Plutella xylostella L. J. Asia Pac. Entomol. 13, 91-95.

Raffa, K. F. and Priester, T. M. (1985): Synergists as research tools and control agents in agriculture. J. Agr. Entomol. 2, 27-45.

Sarfraz, M. and Keddie, B. A. (2005): Conserving the efficacy of insecticides against Plutella xylostella (L.) (Lep:Plutellidae). J. Appl. Entomol. 129, 149-157.

Shelton, A. M., Robertson, J. L., Tang, J. D., Perez, C., Eigenbrode, S. D., Preisler, H. K., Wilsey, W. T. and Cooley, R. J. (1993): Resistance of diamondback moth (Lepidoptera: Plutellidae) to Bacillus thuringiensis subspecies in the field. J. Econ. Entomol. 86, 697-705.

Shelton, A. M., Sances, F. V., Hawley, J., Tang, J. D., Boune, M., Jungers, D., Collins, H. L. and Farias, J. (2000): Assessment of insecticide resistance after the outbreak of diamondback moth (Lepidoptera: Plutellidae) in California in 1997. J. Econ. Entomol. 93, 931-936.

Sparks, T. C. and Nauen, R. (2015): IRAC: Mode of action classification and insecticide resistance management. Pest. Biochem. Physiol. 121, 122-128.

Stumpf, N. and Nauen, R. (2002): Biochemical markers linked to abamectin resistance in Tetranychus urticae (Acari: Tetranychidae). Pestic. Biochem. Physiol. 72, 111-121.

Sun, J., Liang, P. and Gao, X. (2011): Cross resistance patterns and fitness in fufenozide resistant diamondback moth, Plutella xylostella (Lepidoptera: Plutellidae). Pest Manage. Sci. 68, 285-289.

Talekar, N. S. and Shelton, A. M. (1993): Biology, ecology, and management of the diamondback moth. Annu. Rev. Entomol. 38, 275-301.

Troczka, B. J., Williamson, M. S., Field, L. M. and Davies, T. E. (2017): Rapid selection for resistance to diamide insecticides in Plutella xylostella via specific amino acid polymorphisms in the ryanodine receptor. Neurotoxicology 60, 224-233.

Wang, R. and Wu, Y. (2014): Dominant fitness costs of abamectin resistance in Plutella xylostella. Pest Manage. Sci. 70, 1872-1876.

Zhao, J. Z., Collins, H. L., Li, Y. X., Mau, R. F., Thompson, G. D., Hertlein, M. S., Andaloro, J. T., Boyken, R. and Shelton, A. M. (2006): Monitoring of diamondback moth resistance to spinosad, indoxacarb and emamectin benzoate. J. Econ. Entomol. 99, 176-181. 